\title{
The elevated admission white blood cell count relates to adverse surgical outcome of acute Stanford type a aortic dissection
}

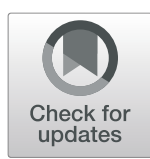

Mingjia Ma, Juan Shi, Xin Feng, Jing Wang, Ligang Liu and Xiang Wei

\begin{abstract}
Background: The purpose of the study was to examine the association between white blood cell count (WBCc) on admission and early outcome in patients with the acute Stanford type A aortic dissection (TAAD).

Methods: From January 2012 to December 2018, we retrospectively evaluated a series of 331 consecutive patients underwent surgery for TAAD in Tongji Hospital. The patients were divided into 2 groups based on the WBCc, i.e. the normal WBCc group (WBCc $\left.\leq 11 \times 10^{9} / \mathrm{L}\right)$ and leukocytosis group $\left(\mathrm{WBC}>11 \times 10^{9} / \mathrm{L}\right)$. The perioperative data were compared between the 2 groups. The in-hospital mortality and the compositive adverse event including multi-organ dysfunction syndrome, postoperative stroke, tracheotomy, and re-exploration for stopping bleeding were set as end points. Cox regression were used to assess the potential risk factors.

Results: The in-hospital mortality was nearly 3 time higher in the leukocytosis group than in the normal WBCC group (20.9\% vs.8.1\%, $P=0.001)$, and $15.1 \%$ overall. For the circulatory arrest, there was significant higher mortality in patients with leukocytosis than normal WBCc group $(26.1 \% \mathrm{vs} .8 .9 \%, P=0.001)$. After adjustment for confounding factors, the leukocytosis was found to be a strong independent predictor of in-hospital mortality (odds ratio $=3.10$; $95 \%$ confidence interval 1.38 to $6.97, P=0.006$ ). The leukocytosis was also a risk factor of adverse events (odds ratio $=1.80 ; 95 \%$ confidence interval 1.07 to $3.04, P=0.027$ ).

Conclusions: The WBCc within $24 \mathrm{~h}$ of admission for TAAD is a strong and independent predictor of in-hospital mortality as well as short-term clinical events. The results of this study have important clinical implications for riskstratifying patients with TAAD.
\end{abstract}

Keywords: White blood cell count, Acute Stanford type a aortic dissection, Surgical outcome, Circulatory arrest, Risk factors

\section{Background}

Acute Stanford type A aortic dissection (TAAD) is cardiovascular disaster associated with high mortality. The surgical management is the most effective therapy. However, despite advances in the technique and perioperative care, the surgical mortality and morbidities of potentially fatal complications of TAAD stayed relatively high, and it may be affected by the preoperative status of the patients [1]. Therefore, efforts have been put to identify high-risk TAAD patients $[2,3]$. Several predictors of

\footnotetext{
*Correspondence: xiangwee_hust@163.com

Division of Cardiothoracic and Vascular Surgery, Tongji Hospital, Tongji Medical College, Huazhong University of Science and Technology, 1095\# Jiefang Ave. Wuhan, Wuhan, 430030, China
}

adverse events in acute aortic dissection have been discussed [4]. To our knowledge, the special impact of the white blood cell count (WBCc) on surgical outcome of acute aortic dissection remained unelucidated. The present study was designed to assess the relationship between WBCc and surgical outcomes in TAAD patients.

\section{Methods}

From January 2012 to December 2018, a series of consecutive patients underwent surgery for acute Stanford type A aortic dissection in Tongji hospital. The chart review was conducted to gathering clinical information. TAAD was defined as acute if onset of the symptoms within 2 weeks before admission and the diagnosis was

(c) The Author(s). 2020 Open Access This article is distributed under the terms of the Creative Commons Attribution 4.0 International License (http://creativecommons.org/licenses/by/4.0/), which permits unrestricted use, distribution, and 
confirmed by computed tomographic angiography. We excluded the cases of iatrogenic aortic dissection, chronic aortic dissection, and patients who had a history of cardiac surgery. Three cases of aortic dissection combined with pregnancy were also excluded. The primary end point was in-hospital mortality and the second end point were the compositive adverse events comprised multi-organ dysfunction syndrome, postoperative stroke, tracheotomy, and re-exploration for stopping bleeding. The patient that has one or more adverse events was count as an adverse event case.

The patients were divided into normal WBCc group $\left(\mathrm{WBC} \leq 11 \times 10^{9} / \mathrm{L}\right.$ ) and elevated WBCc group (WBCc> $11 \times 10^{9} / \mathrm{L}$ ). The perioperative data were compared between the 2 groups. This study was approved by the local clinical research ethics committee and the consent of the subjects were waived.

\section{Definition}

Primarily, the WBCc on admission above $11 \times 10^{9} / \mathrm{L}$ was defined as leukocytosis [5]. Emergent surgeries were operations carried out within $24 \mathrm{~h}$ after admission. Acute renal dysfunction was defined as elevation of serum creatinine level 3-fold greater than baseline or a new requirement for transient hemodialysis. Acute hepatic insufficiency was defined as elevation of aspartate aminotransferase greater than $200 \mathrm{IU} / \mathrm{L}$. Hypoxemia was defined as oxygenation impairment with arterial partial pressure of oxygen/fraction of inspired oxygen ratio $\left(\mathrm{PaO}_{2} / \mathrm{FiO}_{2}\right)<300$ and acute respiratory dysfunction was $\mathrm{PaO}_{2} / \mathrm{FiO}_{2}<150$ that occurred on admission. Transient neurologic dysfunction was defined as resolvable mental disorder without identifiable brain imaging change after operation. Permanent neurologic dysfunction (PND) was neurologic deficit with detectable change in magnetic resonance imaging or computed tomography scans.

\section{Surgical technique}

All the operation was performed via median sternotomy approach. The cardiopulmonary bypass $(\mathrm{CPB})$ was established by arterial cannulation of unilateral femoral artery and/or the right subclavian artery and venous cannulation in right atrium. A left ventricular vent line was inserted through the right superior pulmonary vein.

After cross clamping the ascending aorta, the aorta was longitudinally opened and cardioplegic solution was directly administrated via the coronary ostia for myocardia protection. The lesion of the dissection and geometrical morphology of root were carefully detected. If necessary, resuspension of cusps with commissural stitches or aortic root replacement with composite prosthesis was performed depending on the lesion of the sinus and dilatation of aortic root. The coronary artery bypass graft was performed in circumstances of coronary artery ostia teared or combined severe coronary artery disease.

After the aortic root procedure was completed, the distal extent of the aortic replacement was determined by the location of the intimal tear. When the intimal tear was limited in the ascending aorta, the ascending aorta replacement was performed. If the primary tear located in the arch or the intimal tear extended into aortic arch, hemi-arch replacement or total aortic arch replacement combined with stent frozen elephant trunk implantation was performed under circulatory arrest. During circulatory arrest, the systemic hypothermia maintained at moderate $\left(20-28^{\circ} \mathrm{C}\right)$ level at the rectal site, and antegrade selective cerebral perfusion was applied for neuroprotection. In year 2012, arch debranching with intraoperative endograft deployment was introduced for total arch repair. The surgical method of individual case was determined by both the lesion and surgeon's personal preference and experience.

\section{Statistical analysis}

Continuous variables are presented as the mean \pm standard deviation, while non-normally distributed variables are presented as the median and interquartile ranges. Normally distributed variables are compared using Student's $t$ test. The Mann-Whitney $U$ test is used for nonnormally distributed data. The categorical data are calculated by chi-square test in different groups. For chisquare contingency-table test, the results were interpreted by standardized residual method of post hoc analysis [6]. Univariable and multivariable Cox regression are used to assess the potential risk factors of in-hospital mortality and major adverse event cases. Adjusting parameters and variables those known as risk factors or variables with $P$ value less than 0.1 in univariate analysis are included in the multivariate proportional hazards models. We built two kinds of multivariable Cox regression models, the WBCc is treated as the dependent variable in the form of quartiles (model 1) and two-category data (model 2). The cut-off points of WBCc are evaluated by receiver operating characteristic (ROC) curves. Statistical significance was set as a two-sided $P$-value $<$ 0.05. SPSS Statistics 19.0 (IBM, Somers, NY) was used for statistical analysis.

\section{Results}

There were 331 patients included in this study. The male to female ratio was $4: 1$. The age of the patients was $48.3 \pm 9.4$ years (ranged $25-72$ years). Nearly half of the operations (165 cases, 49.8\%) were performed emergently.

The mean WBCc was $11.69 \pm 4.11 \times 10^{9} / \mathrm{L}$, and distribution of individual WBCc levels in every $1 \times 10^{9} / \mathrm{L}$ were displayed in Fig. 1. Compared to the patients in the 


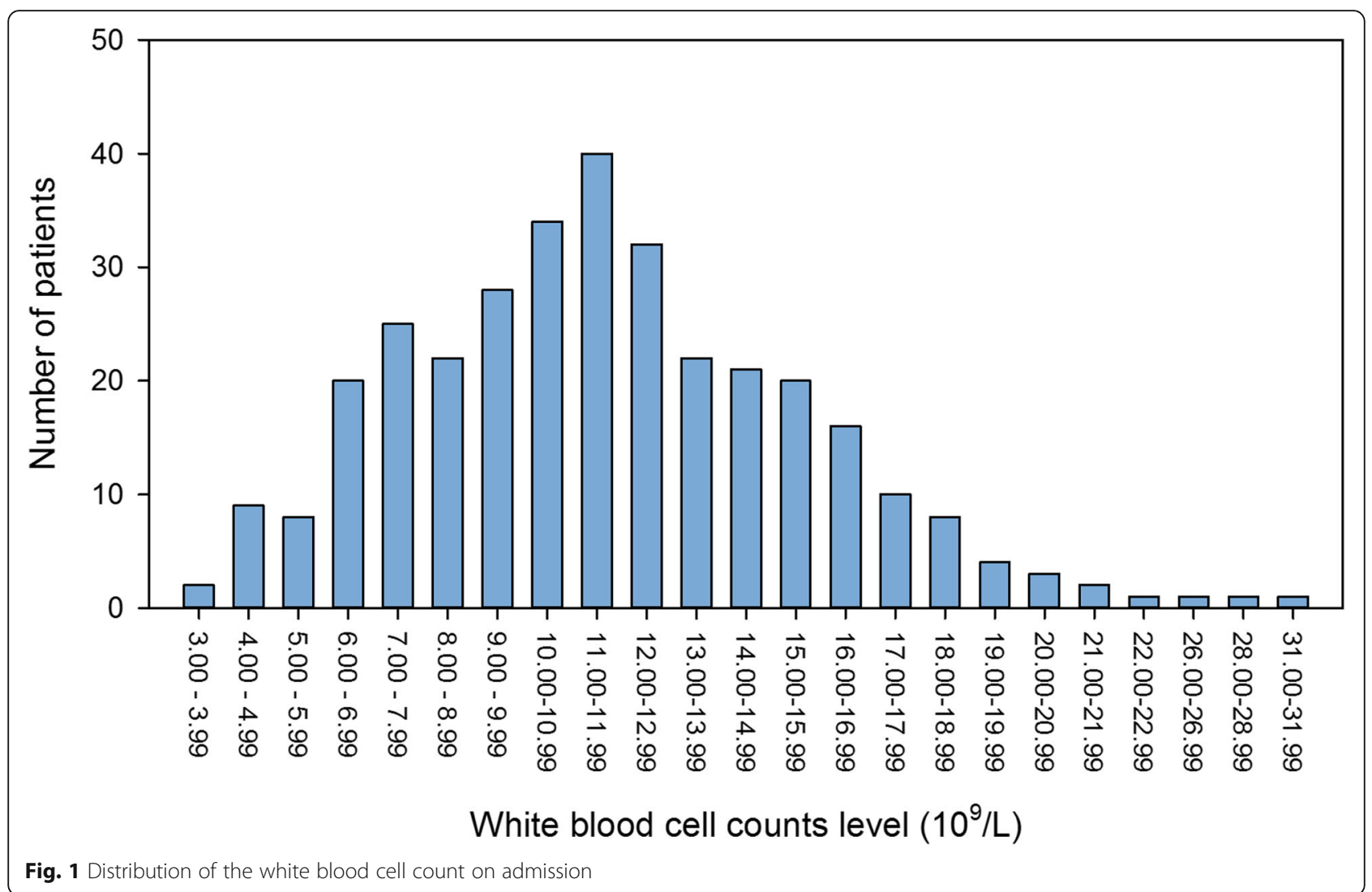

group of the normal WBCc (normal group, $n=149$, $45 \%$ ), patients in the group of the elevated WBCc (leukocytosis group, $n=182,55 \%$ ) were more likely to be younger $(50.2 \pm 9.5$ years vs. $46.7 \pm 9.2$ years, $P=$ 0.001 ). In addition, the patients in leukocytosis group had higher neutrophil-to-lymphocyte ratio $(7.0 \pm 5.3$ vs. $12.2 \pm 6.6, P<0.001)$ on admission and underwent emergent surgery more frequently $(36.2 \%$ vs. $61.0 \%, \mathrm{P}<$ $0.001)$. Interesting, the signs end-organ ischemia/insufficient involved heart, lung, and kidneys were similar observed both in the normal WBCc group and leukocytosis WBCc group, but the incidence of acute hepatic injury was found only in the leukocytosis WBCc group $(n=$ 10). The incidence of hypertension was not significant different between the two WBCc groups. The preoperative data were presented in Table 1.

As a whole, the mean operation time was $503.3 \pm 116.5 \mathrm{~min}$ and the mean cardiopulmonary bypass time was $225.4 \pm 61.8 \mathrm{~min}$. The cross-clamping time was $120.0 \pm 31.6 \mathrm{~min}$. The primary intimal tears were identified by directly inspection and resected. The archinvolved procedures were performed in 298 patients, including 228 total arch replacements, 20 hemiarch replacements and 50 aortic arch debranching procedures. Concomitant coronary artery bypass grafting was performed in 25 patients. Overall, 17 patients required a re- sternotomy because of hemorrhagic problems. Ten patient developed sternal infection, of them, 7 cases (70.0\%) had leukocytosis before surgery. Comparing the patients in the normal group to the leukocytosis group, more total arch procedures were performed in the leukocytosis group (61.7\% vs.74.7\%, $P=0.011)$. The high WBCc level seem to be related to serious aortic involvement. There was no significant difference of operation time, cardiopulmonary bypass time and Cross-clamping time between the two groups. The operation data were displayed in Table 2. We then divided patients into 4 groups based on the quartiles of their WBCc on admission (i.e. quartile $1:<8.79 \times 10^{9} / \mathrm{L}$; quartile 2 : 8.80 $11.49 \times 10^{9} / \mathrm{L}$; quartile $3: 11.5-14.49 \times 10^{9} / \mathrm{L}$; and quartile $\left.4:>14.50 \times 10^{9} / \mathrm{L}\right)$. When we compared the patients among the 4 quartiles groups, more cases of intimal tear extended into the aortic root were observed in the highest quartiles group than the other 3 quartiles groups (Table 3).

The in-hospital mortality was $15.1 \%$ overall. The mortality in the normal group was significantly lower than that in the leukocytosis group $(8.1 \%$ vs. $20.9 \%, P=$ 0.001). Thirty-three patients had the postoperative PND, and $2 / 3$ of them had leukocytosis preoperatively. There was a trend of increasing risk of in-hospital mortality and comorbidities of PND and multi-organ dysfunction 
Table 1 Democratic data

\begin{tabular}{|c|c|c|c|}
\hline \multirow[t]{2}{*}{ Variables } & Group I & Group II & \multirow[t]{2}{*}{$P$ value } \\
\hline & $n=149$ & $n=182$ & \\
\hline Gender Male (\%) & $111(74.5)$ & $151(83.0)$ & 0.059 \\
\hline \multicolumn{4}{|l|}{ Age (years) } \\
\hline Mean \pm SD & $50.2 \pm 9.5$ & $46.7 \pm 9.2$ & \multirow[t]{2}{*}{0.019} \\
\hline Median (IQR) & $50.0(43.0-57.0)$ & $47.0(41.0-51.0)$ & \\
\hline Diabetes mellitus (\%) & $13(8.7)$ & $16(8.8)$ & 0.983 \\
\hline Hypertension (\%) & $110(73.8)$ & $139(76.4)$ & 0.593 \\
\hline \multicolumn{4}{|l|}{ Body mass index } \\
\hline Mean \pm SD & $23.9 \pm 3.9$ & $25.7 \pm 3.6$ & \multirow[t]{2}{*}{$<0.001$} \\
\hline Median (IQR) & $23.9(21.0-25.7)$ & $25.5(23.2-27.8)$ & \\
\hline \multicolumn{4}{|l|}{ Triglyceride (mmol/L) } \\
\hline Mean \pm SD & $1.1 \pm 0.7$ & $1.2 \pm 0.7$ & \multirow[t]{2}{*}{0.030} \\
\hline Median (IQR) & $1.0(0.7-1.4)$ & $1.1(0.8-1.4)$ & \\
\hline \multicolumn{4}{|l|}{ WBCc $\left(\times 10^{9} / L\right)$} \\
\hline Mean \pm SD & $8.3 \pm 1.9$ & $14.5 \pm 3.2$ & \multirow[t]{2}{*}{$<0.001$} \\
\hline Median (IQR) & $8.4(6.9-9.9)$ & $13.8(12.1-16.0)$ & \\
\hline Hypoxemia (\%) & $67(45.0)$ & $108(59.3)$ & 0.009 \\
\hline $\begin{array}{l}\text { Acute respiratory } \\
\text { dysfunction (\%) }\end{array}$ & $6(4.0)$ & $12(6.8)$ & 0.278 \\
\hline Heart ischemia (\%) & $35(23.5)$ & $43(23.6)$ & 0.977 \\
\hline Acute hepatic injury (\%) & 0 & $10(5.5)$ & 0.003 \\
\hline Renal disfunction (\%) & $6(4.0)$ & $12(6.6)$ & 0.306 \\
\hline Emergency (\%) & $54(36.2)$ & $111(61.0)$ & $<0.001$ \\
\hline
\end{tabular}

$I Q R$ interquartile range, $S D$ standard deviation, $W B C C$ white blood cell count Group I: normal WBCC group, Group II: leukocytosis group

Note: $P$-value $<0.05$ is highlighted in bold type

symptoms with increasing WBCc. The duration of ventilation time and intensive care unit stay time were significantly longer in the leukocytosis group compared with patients did in the normal WBCc group, respectively (Table 4). After excluding the dead cases, we could not find a significant relationship between the preoperative WBCc and total in-hospital time.

In the subgroup analysis of patients underwent surgery with /without circulatory arrest, there are significant differences for in-hospital mortality between the preoperative leukocytosis and no leukocytosis. For the circulatory arrest group, there was significant higher mortality in patients with leukocytosis than normal WBCc group ( $26.1 \%$ vs.8.9\%, $P=0.001)$. However, this difference between leukocytosis and normal WBCc was not found (6.5\% vs. $4.8 \%, P>0.999)$ in the patients without circulatory arrest (Fig. 2).

In univariate analysis, the leukocytosis was risk factor of either in-hospital mortality or compositive adverse events (Table 5). By multivariable-adjusted Cox regression analysis, the preoperative WBCc levels stratified by quartiles and renal dysfunction were found as predictor
Table 2 Operation data

\begin{tabular}{|c|c|c|c|}
\hline \multirow[t]{2}{*}{ Variables } & \multirow{2}{*}{$\begin{array}{l}\text { Group I } \\
n=149\end{array}$} & \multirow{2}{*}{$\begin{array}{l}\text { Group II } \\
n=182\end{array}$} & \multirow{2}{*}{$\begin{array}{l}P \\
\text { value }\end{array}$} \\
\hline & & & \\
\hline Sinus tear (\%) & $33(22.1)$ & $55(30.2)$ & 0.098 \\
\hline Bentall (\%) & $46(30.9)$ & $61(33.5)$ & 0.609 \\
\hline CABG (\%) & $12(8.1)$ & $13(7.1)$ & 0.755 \\
\hline \multicolumn{4}{|l|}{ Operation time (min) } \\
\hline Mean \pm SD & $494.4 \pm 110.0$ & $510.7 \pm 121.4$ & 0.837 \\
\hline Median (IQR) & $494.0(421.5-560.0)$ & $501.0(435.0-572.0)$ & \\
\hline \multicolumn{4}{|l|}{ CPB time (min) } \\
\hline Mean \pm SD & $221.8 \pm 60.4$ & $228.3 \pm 62.9$ & 0.193 \\
\hline Median (IQR) & $217.0(184.5-251.0)$ & $223.5(200.0-254.3)$ & \\
\hline Cross-clamping (min) & $120.2 \pm 33.0$ & $119.9 \pm 30.6$ & 0.937 \\
\hline AVR (\%) & $86(57.7)$ & $114(62.6)$ & 0.363 \\
\hline HAR (\%) & $13(8.7)$ & $7(3.8)$ & 0.064 \\
\hline TAR (\%) & $92(61.7)$ & $136(74.7)$ & 0.011 \\
\hline Arch debranching (\%) & $26(17.4)$ & $24(13.2)$ & 0.281 \\
\hline \multicolumn{4}{|l|}{ Transfusion } \\
\hline \multicolumn{4}{|l|}{$\mathrm{RBC}(U)$} \\
\hline Mean \pm SD & $7.0 \pm 6.4$ & $8.4 \pm 7.5$ & 0.549 \\
\hline Median (IQR) & $5.3(3.0-9.6)$ & $7.0(3.5-11.0)$ & \\
\hline \multicolumn{4}{|l|}{ Plasma (ml) } \\
\hline Mean \pm SD & $946.0 \pm 761.6$ & $1278.6 \pm 1110.8$ & 0.036 \\
\hline Median (IQR) & $\begin{array}{l}900.0 \\
(300.0-1400.0)\end{array}$ & $\begin{array}{l}900.0 \\
(450.0-1800.0)\end{array}$ & \\
\hline
\end{tabular}

$A V R$ aortic valve resuspension, $C A B G$ coronary artery bypass graft, $C P B$ cardiopulmonary bypass, HAR hemi-arch replacement, IQR interquartile range, $S D$ standard deviation, TAR total arch replacement, $R B C$ red blood cell Group I: normal WBCc group, Group II: leukocytosis group

Note: $P$-value $<0.05$ is highlighted in bold type

of in-hospital mortality. The prolonged cardiopulmonary bypass (CPB) time was also an independent risk factor associated with in-hospital mortality when considered as a continuous variable. For the composite endpoint of major adverse events, the elevated WBCc on admission was a significant risk factor of the multivariable analysis. The predictors of 30-day mortality and adverse events according to multivariate analysis were presented in Table 6.

The ROC curve analysis displayed that WBCc beard a significant relation to in-hospital mortality in TAAD patients (area under the curve $0.64 \pm 0.04, P=0.001$, Fig. 3 ). The cut-off value is $11.44 \times 10^{9} / \mathrm{L}$ with sensitivity of $73.6 \%$ and specificity of $55.0 \%$.

\section{Discussion}

In this study, the clinical data of a series of patients underwent surgery for acute aortic dissection were assessed. In a 7-year experience at a single institution, an in-hospital mortality of less than $16 \%$ was achieved. The high WBCc level on admission was related to high in- 
Table 3 Comparison of operation data among 4 quartiles of white blood cell count groups

\begin{tabular}{|c|c|c|c|c|c|c|}
\hline \multirow[t]{2}{*}{ Variables } & \multirow{2}{*}{$\begin{array}{l}\text { Q1 } \\
n=83\end{array}$} & \multirow{2}{*}{$\begin{array}{l}\text { Q2 } \\
n=85\end{array}$} & \multirow{2}{*}{$\begin{array}{l}\text { Q3 } \\
n=87\end{array}$} & \multirow{2}{*}{$\begin{array}{l}\text { Q4 } \\
n=76\end{array}$} & \multicolumn{2}{|c|}{$P$ value ${ }^{*}$} \\
\hline & & & & & overall & (Q1, Q2, Q3) vs. Q4 \\
\hline Sinus tear & 19 (22.9) & $19(22.4)$ & $20(23.0)$ & $30(39.5)$ & 0.038 & 0.004 \\
\hline TAR & $47(56.6)$ & $58(68.2)$ & $63(72.4)$ & 60 (78.9) & 0.019 & 0.028 \\
\hline
\end{tabular}

Q quartiles of white blood cell count on admission, TAR total arch replacement. Q1: < 8.79 $\times 10^{9} / \mathrm{L} ; \mathrm{Q} 2: 8.80-11.49 \times 10^{9} / \mathrm{L} ; \mathrm{Q} 3: 11.5-14.49 \times 10^{9} / \mathrm{L} ;$ and Q4: $>14.50 \times 10^{9} / \mathrm{L}$

Note: $P$-value $<0.05$ is highlighted in bold type.* The post hoc tests are processed with $P$ value $<0.013$ as statistical significance, adjusted by the Bonferroni correction

hospital mortality and as a risk factor of a composite adverse event involved heart, brain, lung and systemic condition. To the best of our knowledge, this is the first study focused on the common index of WBCc effect on surgical outcome of acute type A aortic dissection.

According to data from registry studies, the early mortality of large cohorts ranged $19.6-25.1 \%[1,7]$, and our result was similar to them. Given the advances of the surgical technique and surgeons' experiences, it may continue to remain a challenge to further improve the early outcome in TAAD patients. Due to the threatening nature and devastating presentation of the disease, the outcomes of surgical management have been supposed to be partially influenced by the patients' preoperative status. A numerous of studies have analyzed risk factors

Table 4 Outcomes

\begin{tabular}{llll}
\hline Variables & Group I & Group I & $P$ value \\
& $n=149$ & $n=182$ & \\
\hline In-hospital mortality (\%) & $12(8.1)$ & $38(20.9)$ & $\mathbf{0 . 0 0 1}$ \\
TND (\%) & $42(28.2)$ & $65(35.7)$ & 0.145 \\
PND (\%) & $12(8.1)$ & $21(11.5)$ & 0.292 \\
Ventilation time (h) & & & \\
$\quad$ Mean \pm SD & $94.9 \pm 107.4$ & $137.8 \pm 131.6$ & $<\mathbf{0 . 0 0 1}$ \\
$\quad$ Median (IQR) & $46.0(18.0-139.5)$ & $108.0(31.3-196.0)$ & \\
Tracheotomy (\%) & $23(15.4)$ & $41(22.5)$ & 0.104 \\
Re-exploration (\%) & $4(2.7)$ & $13(7.1)$ & 0.068 \\
MODS (\%) & $7(4.7)$ & $18(9.9)$ & 0.075 \\
RRT (\%) & $19(12.8)$ & $26(14.3)$ & 0.685 \\
ICU time (h) & & & \\
$\quad$ Mean \pm SD & $139.4 \pm 94.5$ & $177.6 \pm 132.9$ & $\mathbf{0 . 0 0 9}$ \\
$\quad$ Median (IQR) & $115.0(68.0-185.3)$ & $161.5(81.3-239.3)$ & \\
In hospital time (d) & & & 0.062 \\
Mean \pm SD & $29.0 \pm 14.7$ & $26.0 \pm 11.7$ & \\
Median (IQR) & $27.0(21.0-34.5)$ & $24.0(18.0-30.0)$ & \\
\hline
\end{tabular}

ICU time intensive care unit stay time, IQR interquartile range, MODS multiorgan dysfunction syndrome, $P N D$ permanent neurologic dysfunction, $R R T$ renal replacement therapy, SD standard deviation, TND transient neurologic dysfunction

Group I: normal WBCc group, Group II: leukocytosis group

Note: $P$-value $<0.05$ is highlighted in bold type

* The variable in hospital time was analyzed after exclusion of the in-hospital dead cases as the primary determinants of outcomes for TAAD surgery. The reported risk factors included advanced age, evidences of complications such as neurological deficit, myocardial ischemia, shock, kidney failure, and limb ischemia et al. [1, 8-11]. In the present study, preoperative renal dysfunction, the elevated WBCc on admission, and prolonged $\mathrm{CPB}$ time were associated with early mortality and morbidities of composite adverse events in surgical intervention of TAAD.

Inflammatory process plays an important role in the development of aortic dissection. High inflammatory biomarker has been observed in patients as soon as the onset of the syndrome, suggesting a very early initiation of a cascade of inflammation in TAAD [12]. The aortic tissue destruction and thrombi in the false lumen created by the dissection may induce the inflammatory reaction. The activated circulating WBCs adhered to endothelium and damaged it with toxic oxygen compounds and proteolytic enzymes, this contributed a lot to the injury of the tissues. The WBC such as neutrophil and macrophages have been detected in the teared aortic tissues [13].

On the other hand, the acute aortic dissection might cause malperfusion syndrome. Significant WBCc elevation has been observed in the end-organ ischemic complications those resulted from cerebral, visceral, or coronary malperfusion $[14,15]$. Higher WBCc in patients with TAAD might reflect the higher severity of malperfusion syndromes when the end-organ involved. Takahashi, T. found WBCc on admission was significant higher in acute aortic dissection patients with relatively severe acute kidney injury when compared with patients without acute kidney insufficiency [16]. The patients with high preoperative WBCc had poor prognosis. Guan et al. demonstrated that WBCc was a significant predictor to type A aortic dissection patients with postoperative neurological complications [17]. The WBCc level indicated the severity of the aortic dissection and the organ malperfusion. In this study, there was significant positive relationship between WBCc and organ malperfusion. Furthermore, since the immediate surgery has been recommended to prevent aortic rupture, improve coronary, cerebral, and visceral circulation, it is comprehensible that the emergent case was more frequently 


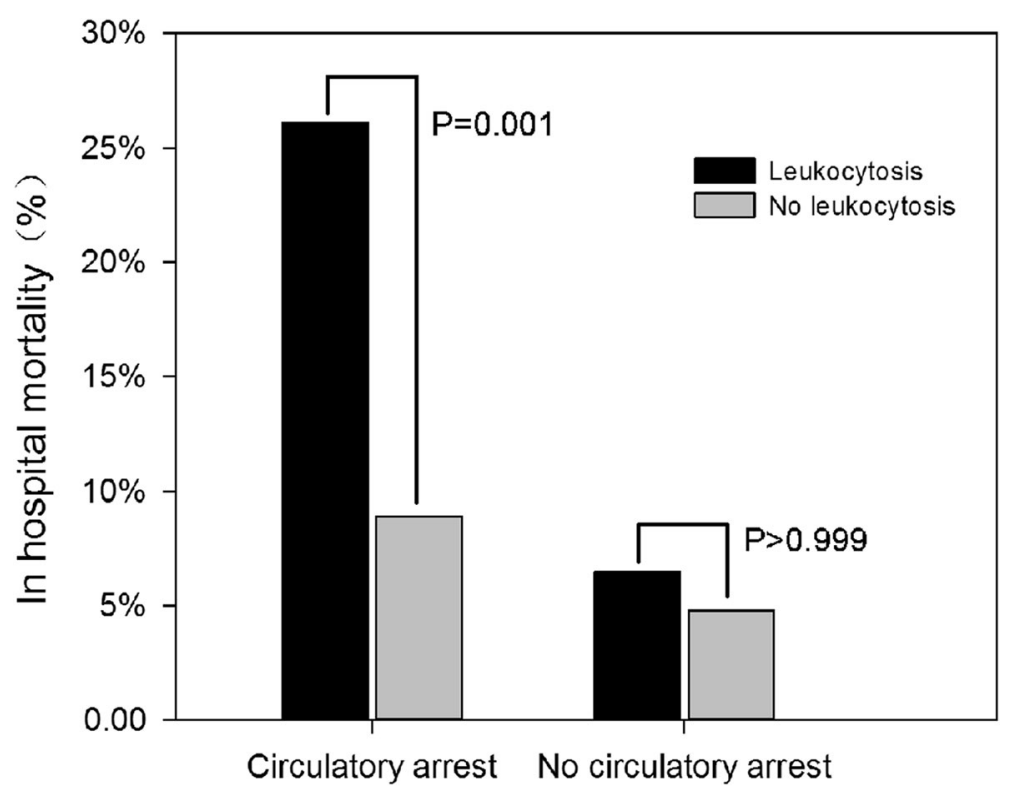

Fig. 2 The in-hospital mortality comparisions between patients with/without leukocytosis (WBCc> $\left.11 \times 10^{9} / \mathrm{L}\right), P$ values were obtained by chisquare test. In the subset of patients with circulatory arrest, the difference of in-hospital mortality was significant $(P=0.001)$

performed in the elevated WBCc group than that in the normal WBCc group in this study.

The surgical modality for TAAD has evolved in the past decades. In this study, we could not find the surgical manners as a significant risk factor for the 30-day mortality and adverse event. That means, the surgical expertise, though evolved with time, remained comparatively stable. However, in the subgroup analysis, the patients with preoperative leukocytosis underwent circulatory arrest displayed worse surgical outcomes than the patients without circulatory arrest. The preoperative high WBCc level might relate with pathophysiological change of organs during circulatory arrest. The potential explanation maybe circulatory arrest process prolonged the $\mathrm{CPB}$ time and aggravate inflammatory response [18]. In the animal model, the inflammation cascades were provoked during rewarming stage after circulatory arrest [19]. The inflammatory cytokines and cells might add insult to ischemiareperfusion injury during the surgery, and lead to poor prognosis.

The elevated $\mathrm{WBCc}$ on administration had related to risk of respiratory complications of TAAD. Duan et al. reported a series of 172 TAAD patients, according to

Table 5 Univariate analysis

\begin{tabular}{|c|c|c|c|c|c|c|}
\hline \multirow[t]{2}{*}{ Variables } & \multicolumn{3}{|l|}{ Mortality } & \multicolumn{3}{|c|}{ Adverse event } \\
\hline & $P$ & $\mathrm{HR}$ & $95 \% \mathrm{Cl}$ & $P$ & $\mathrm{HR}$ & $95 \% \mathrm{Cl}$ \\
\hline Gender & 0.200 & 1.739 & $0.750-4.060$ & 0.050 & 1.806 & $0.999-3.265$ \\
\hline Age & 0.775 & 0.995 & $0.960-1.030$ & 0.871 & 0.998 & $0.975-1.022$ \\
\hline BMl & 0.002 & 1.138 & $1.049-1.234$ & $<0.001$ & 1.127 & $1.059-1.200$ \\
\hline Emergency & 0.741 & 1.107 & $0.606-2.021$ & 0.339 & 1.245 & $0.794-1.950$ \\
\hline WBCC & 0.005 & 1.105 & $1.030-1.185$ & 0.001 & 1.101 & $1.040-1.166$ \\
\hline CPB time & $<0.001$ & 1.015 & $1.009-1.021$ & $<0.001$ & 1.010 & $1.005-1.014$ \\
\hline Cross-clamping time & 0.030 & 1.011 & $1.001-1.020$ & 0.050 & 1.007 & $1.000-1.014$ \\
\hline Diabetes mellitus & 0.382 & 1.53 & $0.589-3.970$ & 0.836 & 0.919 & $0.412-2.046$ \\
\hline Hypertension & 0.622 & 1.199 & $0.583-2.466$ & 0.470 & 1.214 & $0.717-2.058$ \\
\hline Operation type & 0.282 & 1.259 & $0.828-1.915$ & 0.550 & 1.094 & $0.816-1.467$ \\
\hline Renal dysfunction & 0.001 & 5.162 & $1.928-13.821$ & 0.009 & 3.796 & $1.386-10.395$ \\
\hline
\end{tabular}


Table 6 Multivariate analysis

\begin{tabular}{|c|c|c|c|c|c|c|c|}
\hline In-hospital M & HRs & $95 \% \mathrm{Cl}$ & $P$ value & Adverse event & HRs & $95 \% \mathrm{Cl}$ & $P$ value \\
\hline \multicolumn{8}{|l|}{ Model 1} \\
\hline Quartile 1 & 1.000 & & & Quartile 1 & 1.000 & & \\
\hline Quartile 2 & 3.524 & $0.847-14.665$ & 0.083 & Quartile 2 & 1.577 & $0.758-3.282$ & 0.223 \\
\hline Quartile 3 & 8.864 & $2.201-35.693$ & 0.002 & Quartile 3 & 1.764 & $0.843-3.692$ & 0.132 \\
\hline Quartile 4 & 7.579 & $1.832-31.351$ & 0.005 & Quartile 4 & 2.257 & $1.048-4.864$ & 0.038 \\
\hline CPB & 1.018 & $1.010-1.026$ & $<0.001$ & CPB & 1.010 & $1.004-1.016$ & 0.001 \\
\hline Cross-clamping & 1.006 & 0.992-0.979 & 0.272 & Cross-clamping & 0.995 & $0.986-1.006$ & 0.376 \\
\hline \multirow[t]{2}{*}{ Renal dysfunction } & 6.955 & $2.126-22.756$ & 0.001 & Renal dysfunction & 4.029 & $1.365-11.889$ & 0.012 \\
\hline & & & & BMl & 1.090 & $1.017-1.169$ & 0.015 \\
\hline \multicolumn{8}{|l|}{ Model 2} \\
\hline Elevated WBCc & 3.104 & $1.382-6.972$ & 0.006 & Elevated WBCc & 1.801 & $1.068-3.037$ & 0.027 \\
\hline CPB & 1.018 & $1.010-1.026$ & $<0.001$ & CPB & 1.011 & $1.005-1.017$ & $<0.001$ \\
\hline Cross-clamping & 0.993 & $0.980-1.007$ & 0.333 & Cross-clamping & 0.995 & $0.985-1.005$ & 0.371 \\
\hline \multirow[t]{2}{*}{ Renal dysfunction } & 6.718 & $2.132-21.169$ & 0.001 & Renal dysfunction & 4.011 & $1.373-11.719$ & 0.011 \\
\hline & & & & BMl & 1.089 & $1.016-1.168$ & 0.016 \\
\hline
\end{tabular}

$B M I$ body mass index, $C l$ confidence interval, $C P B$ cardiopulmonary bypass, $H R$ hazard ratio, In-hospital $M$ in-hospital mortality, WBCC white blood cell count. Note: $P$-value $<0.05$ is highlighted in bold type

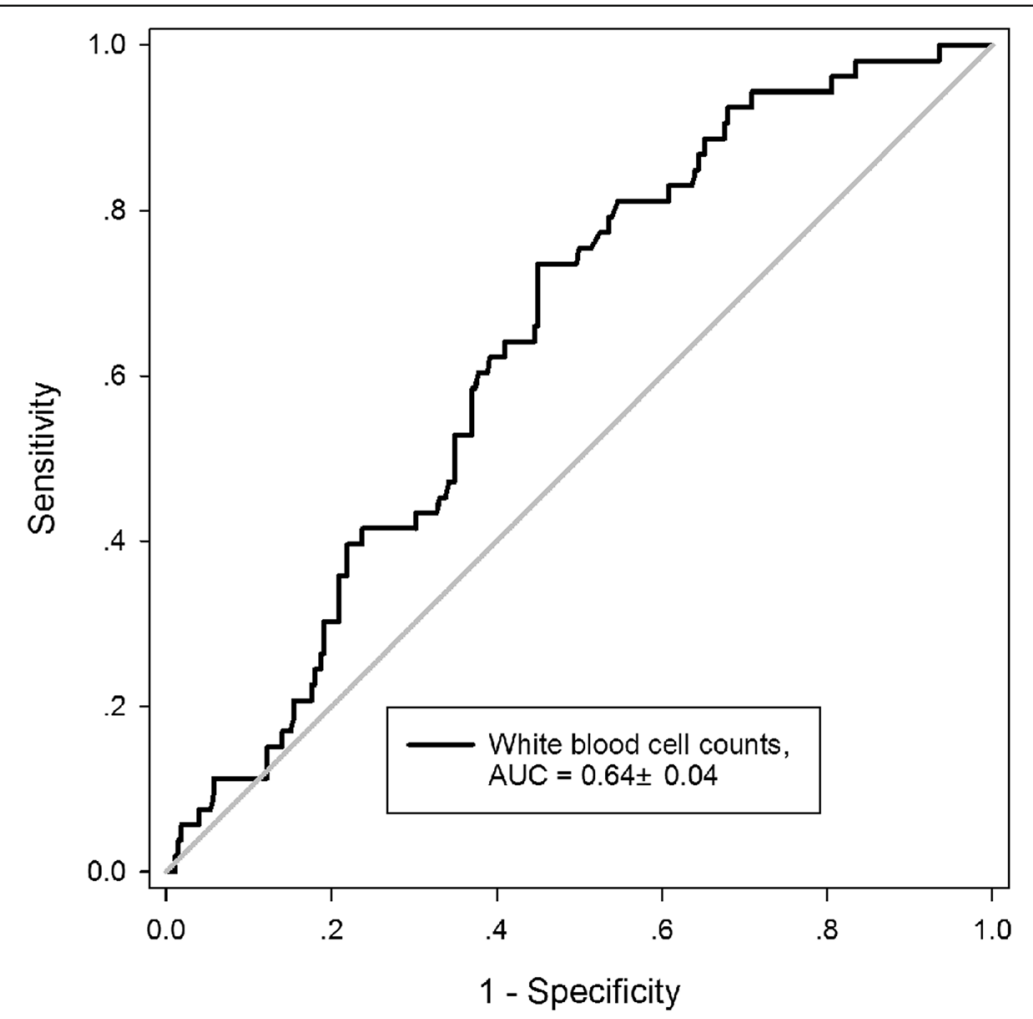

Fig. 3 Receiver operating characteristic (ROC) curve for the prediction by admission white blood cell count of in-hospital mortality in patients underwent surgery for acute type A aortic dissection. AUC, area under ROC curve 
their experience, the inflammatory cells and cytokines such as WBCc and neutrophil counts; levels of Creactive protein and interleukin- 6 were responsible for the hypoxemia before surgery, and the remission of hypoxemia can be achieved by administration of antiinflammatory agent Ulinastatin [20]. On the other hand, the system inflammatory response that attacked the lungs increased the risk of respiratory infection. Respiratory complications were important causes of surgical mortality for TAAD [21]. In our own data, prolonged mechanical ventilation assistance time after surgery was also associated with elevated preoperative WBCc. Considering the peripheral WBCc was a very common index for both the infections and inflammatory processes in the acute stage of aortic dissection, it might be an optimal predictor of respiratory complications. In our center, the managements to improve pulmonary function such as emergency intubation on admission have been actively applied in the high-risk patients to reduce surgical mortality and perioperative complication morbidity.

\section{Limitation}

This is a retrospective study enrolled the patient's clinical data in single institution. Although the blood samples of patients were collected as soon as on admission, the interval between symptom onset and the first blood routine examination could not be accurately evaluated. We included a relatively small number of patients who underwent surgeries in a single center, it might create selective bias. The WBCc as a common inflammatory biomarker has an advantage predictive of short-term outcome, whereas the association between baseline WBCc and long-term survival rate seemed limited.

\section{Conclusion}

The WBCc is such a widely available inflammatory biomarker with the features of being stable, standardized, economical, and fast. The elevated WBCc represented emergency and extensive involvement of the aortic dissection. The high mortality rate was observed in patients presenting with the leukocytosis in circumstance of circulatory arrest. The preoperative WBCc more than $11.5 \times 10^{9} / \mathrm{L}$ could be treated as potential predictor for surgical outcome of TAAD with adequate sensitivity and specificity.

\section{Abbreviations}

CABG: Coronary artery bypass graft; CPB: Cardiopulmonary bypass; $\mathrm{PaO} 2 /$ FiO2: Arterial partial pressure of oxygen/fraction of inspired oxygen ratio; PND: Permanent neurologic dysfunction; ROC: Receiver operating characteristic curves; TAAD: Acute Stanford type A aortic dissection: WBCc: The white blood cell count

\section{Acknowledgements}

None.

\section{Authors' contributions}

Mingjia Ma designed the study. Xin Feng, Jing Wang collected the data and performed the statistical analysis. Mingjia Ma and Juan Shi wrote the manuscript, and contributed equally to this work. Ligang Liu and Xiang Wei carried out the conception and interpretation. All authors read and approved the final manuscript.

\section{Funding}

None.

\section{Availability of data and materials}

The datasets used and/or analyzed during the current study are available from the corresponding author on reasonable request.

Ethics approval and consent to participate

This study was approved by the Ethical Committee of Tongji Hospital, Tongji Medical College, Huazhong University of Science and Technology. The consent of the subjects was waived.

\section{Consent for publication}

Not applicable.

\section{Competing interests}

The authors declare that they have no competing interests.

Received: 22 August 2019 Accepted: 17 February 2020

Published online: 14 March 2020

\section{References}

1. Conzelmann LO, Weigang E, Mehlhorn U, Abugameh A, Hoffmann I, Blettner $\mathrm{M}$, et al. Mortality in patients with acute aortic dissection type a: analysis of pre- and intraoperative risk factors from the German registry for acute aortic dissection type a (GERAADA). Eur J Cardiothorac Surg. 2016;49: e44-52.

2. Bayegan $K$, Domanovits $H$, Schillinger M, Ehrlich M, Sodeck G, Laggner AN. Acute type a aortic dissection: the prognostic impact of preoperative cardiac tamponade. Eur J Cardiothorac Surg. 2001;20:1194-8.

3. Ji Q, Lai H, Sun Y, Luo Z, Liu L, Liu C, et al. Impact of Presurgical mild acute respiratory distress syndrome on surgical mortality after surgical repair of acute type a aortic dissection. Int Heart J. 2017:58:739-45.

4. Lingzhi C, Hao Z, Weijian H, Gaoshu Z, Chengchao S, Changxi C, et al. Outcome predictors in patients presenting with acute aortic dissection. J Cardiothorac Vasc Anesth. 2016:30:1272-7.

5. Asadollahi K, Hastings IM, Beeching NJ, Gill GV, Asadollahi P. Leukocytosis as an alarming sign for mortality in patients hospitalized in general wards. Iran J Med Sci. 2011;36(1):45-9.

6. Beasley TM, Schumacker RE. Multiple regression approach to analyzing contingency tables: post hoc and planned comparison procedures. J Exp Educ. 1995;64(1):79-93.

7. Trimarchi S, Nienaber CA, Rampoldi V, Myrmel T, Suzuki T, Mehta RH, et al. Contemporary results of surgery in acute type a aortic dissection: the international registry of acute aortic dissection experience. J Thorac Cardiovasc Surg. 2005;129:112-22.

8. Pompilio G, Spirito R, Alamanni F, Agrifoglio M, Polvani G, Porqueddu M, et al. Determinants of early and late outcome after surgery for type a aortic dissection. World J Surg. 2001;25:1500-6.

9. Pansini S, Gagliardotto PV, Pompei E, Parisi F, Bardi G, Castenetto E, et al. Early and late risk factors in surgical treatment of acute type a aortic dissection. Ann Thorac Surg. 1998;66:779-84.

10. Goda M, Imoto K, Suzuki S, Uchida K, Yanagi H, Yasuda S, et al. Risk analysis for hospital mortality in patients with acute type a aortic dissection. Ann Thorac Surg. 2010;90:1246-50.

11. Concistre G, Casali G, Santaniello E, Montalto A, Fiorani B, Dell'Aquila A, et al. Reoperation after surgical correction of acute type a aortic dissection: risk factor analysis. Ann Thorac Surg. 2012;93:450-5.

12. Sbarouni $E_{1}$ Georgiadou P, Analitis A, Voudris V. High neutrophil to lymphocyte ratio in type a acute aortic dissection facilitates diagnosis and predicts worse outcome. Expert Rev Mol Diagn. 2015;15:965-70.

13. He R, Guo DC, Estrera AL, Safi HJ, Huynh TT, Yin Z, et al. Characterization of the inflammatory and apoptotic cells in the aortas of patients with 
ascending thoracic aortic aneurysms and dissections. J Thorac Cardiovasc Surg. 2006;131:671-8.

14. Koren-Morag N, Tanne D, Goldbourt U. White blood cell count and the incidence of ischemic stroke in coronary heart disease patients. Am J Med. 2005;118:1004-9.

15. Tshomba Y, Coppi G, Marone EM, Bertoglio L, Kahlberg A, Carlucci M, et al. Diagnostic laparoscopy for early detection of acute mesenteric ischaemia in patients with aortic dissection. Eur J Vasc Endovasc Surg. 2012;43:690-7.

16. Takahashi T, Hasegawa T, Hirata N, Endo A, Yamasaki Y, Ashida K, et al. Impact of acute kidney injury on in-hospital outcomes in patients with DeBakey type III acute aortic dissection. Am J Cardiol. 2014;113:1904-10.

17. Guan $X$, Gong M, Wang X, Zhu J, Liu Y, Sun L, et al. Low preoperative fibrinogen level is risk factor for neurological complications in acute aortic dissection. Medicine (Baltimore). 2018;97:e10830.

18. Shenaq SA, Yawn DH, Saleem A, Joswiak R, Crawford ES. Effect of profound hypothermia on leukocytes and platelets. Ann Clin Lab Sci. 1986;16:130-3.

19. Engels $M$, Bilgic E, Pinto A, Vasquez E, Wollschlager L, Steinbrenner $H$, et al. A cardiopulmonary bypass with deep hypothermic circulatory arrest rat model for the investigation of the systemic inflammation response and induced organ damage. J Inflamm (Lond). 2014;11:26.

20. Duan $X Z, X u Z Y$, Lu FL, Han L, Tang YF, Tang H, et al. Inflammation is related to preoperative hypoxemia in patients with acute Stanford type a aortic dissection. J Thorac Dis. 2018;10:1628-34.

21. Chen MF, Chen LW, Cao H, Lin Y. Analysis of risk factors for and the prognosis of postoperative acute respiratory distress syndrome in patients with Stanford type a aortic dissection. J Thorac Dis. 2016;8:2862-71.

\section{Publisher's Note}

Springer Nature remains neutral with regard to jurisdictional claims in published maps and institutional affiliations.

Ready to submit your research? Choose BMC and benefit from:

- fast, convenient online submission

- thorough peer review by experienced researchers in your field

- rapid publication on acceptance

- support for research data, including large and complex data types

- gold Open Access which fosters wider collaboration and increased citations

- maximum visibility for your research: over $100 \mathrm{M}$ website views per year

At $\mathrm{BMC}$, research is always in progress.

Learn more biomedcentral.com/submissions 